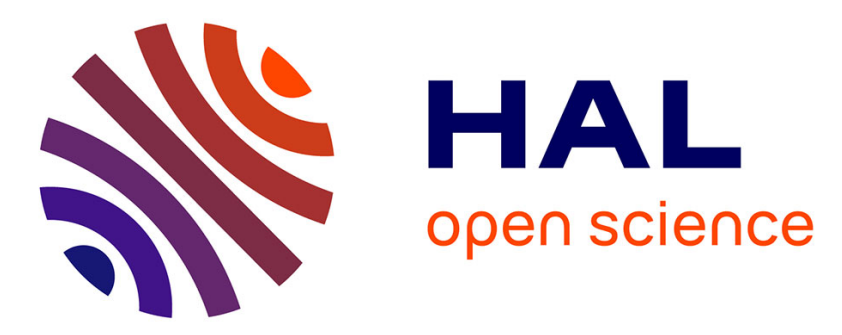

\title{
Volcanic terrain and the possible periglacial formation of "excess ice" at the mid-latitudes of Utopia Planitia, Mars
}

\author{
R.J. Soare, B. Horgan, S.J. Conway, C. Souness, M.R. El-Maarry
}

\section{- To cite this version:}

R.J. Soare, B. Horgan, S.J. Conway, C. Souness, M.R. El-Maarry. Volcanic terrain and the possible periglacial formation of "excess ice" at the mid-latitudes of Utopia Planitia, Mars. Earth and Planetary Science Letters, 2015, 423, pp.182-192. 10.1016/j.epsl.2015.04.033 . insu-02274301

\section{HAL Id: insu-02274301 \\ https://hal-insu.archives-ouvertes.fr/insu-02274301}

Submitted on 8 Jan 2021

HAL is a multi-disciplinary open access archive for the deposit and dissemination of scientific research documents, whether they are published or not. The documents may come from teaching and research institutions in France or abroad, or from public or private research centers.
L'archive ouverte pluridisciplinaire HAL, est destinée au dépôt et à la diffusion de documents scientifiques de niveau recherche, publiés ou non, émanant des établissements d'enseignement et de recherche français ou étrangers, des laboratoires publics ou privés. 
Volcanic terrain and the possible periglacial formation of "excess ice" at the mid-latitudes of Utopia Planitia, Mars

\author{
R.J. Soare, ${ }^{1}$ B. Horgan, ${ }^{2}$ S.J. Conway, ${ }^{3}$ C. Souness, ${ }^{4}$ and M.R. El-Maarry ${ }^{5}$ \\ ${ }^{1}$ Department of Geography, Dawson College, Montreal, Canada, H3Z 1A4 \\ (rsoare@dawsoncollege.qc.ca) \\ ${ }^{2}$ Earth, Atmospheric \& Planetary Sciences, Purdue University, \\ West Lafayette, Indiana, USA 47907-2051 \\ ${ }^{3}$ Department of Physical Sciences, Open University, \\ Milton Keynes, UK, MK7 6AA \\ ${ }^{4}$ Centre for Glaciology, Department of Geosciences, Aberystwyth University, \\ Aberystwyth, UK, SY23 3DB \\ ${ }^{5}$ Physikalisches Institut, Bern Universität, Berne, Switzerland, 3012
}

Pages-34

$7 \quad$ Figures-7

Tables- 0

Key Words-Mars: climate, atmosphere, surface 


\section{Abstract}

At the mid-latitudes of Utopia Planitia (UP), Mars, a suite of spatially-associated landforms exhibit geomorphological traits that, on Earth, would be consistent with periglacial processes and the possible freeze-thaw cycling of water. The suite comprises small-sized polygonally-patterned ground, polygon-junction and -margin pits, and scalloped, rimless depressions. Typically, the landforms incise a dark-toned terrain that is thought to be ice-rich. Here, we investigate the dark-toned terrain by using high resolution images from the HiRISE as well as near-infrared spectral-data from the OMEGA and CRISM. The terrain displays erosional characteristics consistent with a sedimentary nature and a unique spectral-shape that could be indicative of weathered basaltic-tephra. We also describe volcanic terrain that is dark-toned and periglacially-modified in the Kamchatka mountain-range of eastern Russia. The terrain is characterised by weathered tephra inter-bedded with snow, ice-wedge polygons and near-surface excess ice. The excess ice forms in the pore space of the tephra as the result of snow-melt infiltration and, subsequently, in-situ freezing. Based on this possible analogue, we construct a three-stage mechanism that explains the possible ice-enrichment of a broad expanse of dark-toned terrain at the mid-latitudes of UP: (1) the dark-toned terrain accumulates and forms via the regional deposition of sediments sourced from explosive volcanism; (2) the volcanic sediments are blanketed by atmospherically-precipitated $\left(\mathrm{H}_{2} \mathrm{O}\right)$ snow, ice or an admixture of the two, either concurrent with the volcanic-events or between discrete events; and, (3) under the influence of high obliquity or explosive volcanism, boundary conditions tolerant of thaw evolve and this, in turn, permits the migration, cycling and eventual formation of excess ice in the volcanic sediments. Over time, and through episodic iterations of this scenario, excess ice forms to decametres of depth.

\section{Introduction}

At the mid-latitudes $\left(38-45^{\circ} \mathrm{N} ; 85-93^{\circ} \mathrm{E}\right)$ of Utopia Planitia $(U P)$, Mars, an expansive 
reach of dark-toned terrain (Fig. 1a) is incised by three spatially-associated landforms (Fig. 2a-c) whose geomorphological traits, were they observed on Earth, would be consistent with periglacial processes, the possible freeze-thaw cycling of water and, most importantly, the presence of excess ice (Fig. 2d). Excess ice occurs where "the volume of ice in the ground exceeds the total pore-volume that the ground would have under unfrozen-conditions" (Harris et al., 1988).

The suite of putative periglacial-landforms (PPLs) comprises: (a) small-sized $(\leq 50 \mathrm{~m})$ and non-sorted polygonally-patterned ground (Mellon, 1997; Seibert and Kargel, 2001; Morgenstern et al., 2007; Soare et al., 2008, 2009, 2012b; Lefort et al., 2009; Levy et al., 2009a,b; Hauber et al., 2011; Ulrich et al., 2011); (b) multi-metre scale polygon-junction and margin pits (Wan Bun Tseung and Soare, 2006; Morgenstern et al., 2007; Séjourné et al., 2010); and, (c) scalloped depressions that are rimless, flat-floored, metres to tens of decametres deep and metres to kilometres in their long axes (Costard and Kargel; Morgenstern et al., 2007; Soare et al., 2007, 2008, 2011; Lefort et al., 2009; Ulrich et al., 2010; Séjourné et al., 2011, 2012).

There is widespread agreement amongst Mars researchers that the scalloped depressions are thermokarst-like basins (alases) that formed, along with the other two PPLs, in response to the thermal destabilization of ice-rich terrain (e.g. Morgenstern et al., 2007; Soare et al., 2007, 2008; Lefort et al., 2009; Séjourné et al., 2011, 2012). Opinions diverge, however, in response to two questions:

(1) Do the thermokarst-like basins form by means of (a) melting and evaporation or (b) sublimation?

(2) By which means did the dark-toned terrain cross-cut by the PPLs become icerich?

Although the answer to the first question remains open-ended, we believe that the data and 
observations presented in this study can begin to address and, perhaps answer, the second question.

Numerous researchers propose that the PPLs in mid-UP originate and evolve in an extremely young and ubiquitous light-toned mantle comprised of ice-dust (e.g. Morgenstern et al., 2007; Lefort et al., 2009; also, Levy et al., 2009a-b, 2010). By contrast, our previous observations show that the PPLs generally incise terrain that is dark, not light, in tone (Soare et al., 2012a-b); moreover, where the two differently-toned terrains are proximal, we find that the dark-toned terrain is at a lower relative-elevation than the light-toned terrain, suggesting that the PPLs pre-date rather than post-date the mantle (Soare et al., 2012a-b). Thus, the darktoned terrain is not derived from the (possibly) ice-rich light-toned mantle, but is a separate and older ice-rich unit.

Here, we use an assemblage of high-resolution images and spectral data to investigate the dark and light-toned terrains. We show that the dark-toned and possibly "ice-rich" terrain in mid- $U P$ has a unique spectral-shape that is consistent with weathered basaltic-tephra. Next, we present and describe a possible terrestrial-analogue comprised of a dark toned and periglacially-modified volcanic terrain in the Kamchatka mountain-range of eastern Russia. The terrain is typified by ice-wedge polygons, weathered volcanic tephra inter-bedded with snow, and near-surface excess ice; it forms in the pore space of the tephra as the result of snow-melt infiltration and, subsequently, in-situ freezing. We suggest that the Kamchatkan terrain is a useful geological/geomorphological analogue of mid-UP. Consequently, we construct a three-stage hypothesis modelled after the former that explains the volcanic origin of the dark-toned terrain on Mars and its ice enrichment by the freeze-thaw cycling of surface and near-surface melt-water.

\section{Methods}


In order to constrain the possible origin of excess ice in the dark-toned terrain of mid $U P$ we have used four datasets: (1) visible imagery from the High Resolution Imaging Science Experiment (HiRISE, Mars Reconnaissance Orbiter; McEwen et al, 2007) and (2) the Context Camera (CTX, Mars Reconnaissance Orbiter; Malin et al., 2007); (3) km-scale visible to near-infrared spectral context from the Observatoire pour la Mineralogie, l'Eau, les Glaces, et l'Activité (OMEGA, Mars Express; Bibring et al., 2005); and, (4) decameter-scale visible to near-infrared spectra from the Compact Reconnaissance Imaging Spectrometer for Mars (CRISM, Mars Reconnaissance Orbiter; Murchie et al., 2007).

Morphology and (visible) surface-properties were evaluated on a regional scale using a mosaic of CTX images (6m/pixel, adapted from Soare et al., 2012b) (Fig. 1c). HiRISE images $(25-50 \mathrm{~cm} /$ pixel $)$ were used as required to investigate and highlight morphologies and surface textures at higher resolutions (Figs. 2, 5).

For context, visible to near-infrared $(0.35-2.5 \mu \mathrm{m})$ spectral properties of the regional surface were identified by means of a (1km/pixel) $O M E G A$ mosaic covering $60-120^{\circ} \mathrm{E}$ and $30-65^{\circ} \mathrm{N}$. The mosaic was constructed from all publicly available $O M E G A$ observations, calibrated using the SOFT04 software package, converted to an estimated Lambert albedo, then filtered and ordered using the methods described by Ody et al. (2012). The visible portion of each spectrum was adjusted for best spectral alignment with the near-infrared portion of the spectrum, as described in detail in Horgan et al. (2014). This step is necessary because the visible and near-infrared portions of the spectra are collected by two different CCD's with slightly different viewing geometries and calibrations, thus leading to small (typically 0-3\%) offsets between their spectra. Figures $1 \mathbf{b}$ and 1d shows the magnitude of the spectral slope of the OMEGA spectra in this mosaic between 0.77 and $1.30 \mu \mathrm{m}$, calculated as the ratio of the three closest channels to each of these wavelengths. This slope parameter spans both the visible and near-infrared portions of the OMEGA spectra, and thus would be 
affected by poor spectral alignment at the visible/near-IR join. However, the alignment step above accounts for most alignment issues, as demonstrated by the fact that the parameter does not vary significantly across image boundaries in the map.

Local spectral variations were investigated using CRISM observations (18m/pixel), as shown in Figure 3, which were downloaded from the Planetary Data System at the TRR3 calibration level. Further processing to estimated Lambertian-albedo utilized the CRISM Analysis Toolkit for ENVI (Seelos et al., 2011), including photometric and scaled volcano scan atmospheric corrections. No additional spectral processing was applied to these images (e.g., ratios, continuum removal, etc.), so all spectra shown in Figure $\mathbf{3}$ are unmodified albedo spectra. Two continuous groups of channels near 1 and $2 \mu \mathrm{m}$ were removed due to noise near the visible/near-IR join and residual features from the atmospheric correction (e.g., Seelos et al., 2014). All spectra are averages of at least $3 \times 3$ up to 10x10 pixel areas.

\section{Spectral properties of the dark-toned terrain in $U P$}

Previous studies have shown that the low-albedo regions of the northern plains, principally in Acidalia and Utopia Planitiae, show spectra that are highly homogeneous: in the near-infrared, the spectra slope linearly downward to longer wavelengths (a "blue" slope; e.g., Mustard et al., 2005). In some locations, the spectra are more sloped at the shorter wavelengths than at the longer ones, creating a nonlinear "concave up" shape (Horgan and Bell, 2012; Horgan et al., 2013). A simple method for identifying these concave up spectra is to map the spectral slope between 0.77 and $1.3 \mu \mathrm{m}$, as shown in Figures $\mathbf{1 b}$ and 1d.

Unlike other dark regions of Mars, the northern plains do not exhibit strong absorption bands resulting from the iron in mafic minerals (Mustard et al., 2005; Poulet et al., 2008); typically, these occur near 1 and sometimes also $2 \mu \mathrm{m}$ (e.g., Adams, 1968). Our study region is dominated by dark surface sediments that exhibit similar spectral characteristics to other locations in the northern plains, including low albedo, blue and often concave up 
spectral slopes, and no or very shallow iron absorption-bands, as demonstrated by spectra 13, 6, and 8 in Figure 3. As discussed in greater detail below, these characteristics are consistent with weathered glass-rich deposits.

Linear blue spectral-slopes can be indicative of coatings deposited during aqueous alteration (silica or oxide coatings) or dry oxidative weathering (oxide rinds) (Kraft et al., 2007; Milliken et al., 2008; Minitti et al., 2007; Salvatore et al., 2013). They also could be due to optically-thin layers of bright dust on a dark substrate (Fischer and Pieters, 1993). Based on these spectral analogues, the linear blue spectral-slopes found throughout much of the northern plains have been interpreted as either oxide coatings or rinds (Mustard et al., 2005; Poulet et al., 2008; Salvatore et al., 2013).

On the other hand, nonlinear concave up slopes at wavelengths below $1.3 \mu \mathrm{m}$ are not caused by these effects, but instead are often associated with leached rinds on glass, usually due to acidic aqueous alteration (Minitti et al., 2007; Seelos et al., 2010; Horgan and Bell, 2012; Horgan et al., 2013). For example, Figure 4 shows spectra of basaltic glasses at Mauna Kea, Hawaii, including cooling rinds on lavas, glassy lavas, and tephra. Unaltered ash exhibits broad absorption bands and often a red spectral slope; by contrast, ash and glass exposed to acidic weathering conditions (on Mauna Kea, due to volcanic sulfur emissions) exhibit no or very weak bands and a concave-up spectral slope that, sometimes, also is blue. Although this spectral signature usually is associated with sands or larger sedimentary-grains, it dominates the bulk spectrum of ash even when the ash is poorly sorted (Fig. 4c).

In the northern plains, concave-up slopes have been shown to be primarily associated with dune fields and other dark surface sediments (Horgan and Bell, 2012). One key line of evidence for the leached-glass interpretation of the concave-up spectral slopes is their common association with weak iron-absorption bands centered near $1.15 \mu \mathrm{m}$ (Horgan and Bell, 2012); these are uniquely consistent with iron-bearing glass (e.g., Adams et al., 1974). 
These $1.15 \mu \mathrm{m}$ bands are the only mafic absorption bands observed in the dark surface sediments of the northern plains, and are observed in about 5\% of OMEGA spectra in Acidalia and Utopia, in nearly $30 \%$ of the north-polar sand sea, and are highly correlated with concave-up slopes (Horgan and Bell, 2012; Horgan et al., 2014). Furthermore, areas that exhibit the strongest concave-up slopes do not exhibit iron absorption bands, consistent with obscuration of the glass substrate by a leaching rind (Minitti et al., 2007; Horgan and Bell, 2012; Horgan et al., 2013). Although the dark-toned surface sediments in our study region typically do not exhibit clear and diagnostic iron absorption bands due to glass or other minerals, they are otherwise spectrally very similar to other widespread areas in the northern lowlands previously interpreted as weathered glass. Thus, we hypothesize that the dark surface sediments in our study region are also weathered glass.

In our study region, there are indications of spectral diversity at depths below the dark-toned terrain, suggesting that the dark sediments that the PPL's incise are limited in their thickness, on the order of decameters. Some still dark but slightly lighter-toned subsurface units exposed in the walls of craters exhibit a different spectral shape than the dark surface sediments, with a broad absorption between 0.8 and $1.8 \mu \mathrm{m}$, such as spectra 4 and 5 in Figure 3. These spectra are similar to spectra from crater walls in central and southern Acidalia Planitia; these are interpreted to be olivine-bearing (Salvatore et al., 2010). The $\sim 1$ $\mu \mathrm{m}$ absorptions of the buried units in $U P$ are somewhat broader than in Acidalia, but could be consistent with an olivine and/or glass-rich basalt, or some other mafic phase. These spectra are observed in association with moderate-toned cliff-forming units and sediments that appear to be derived from these units, including transverse aeolian-ridges and wind-streaks. This suggests a sedimentary nature for this material as well as the dark terrain above, but the origin and emplacement history is less well-constrained in these lower units. 
the dark-toned terrain displays a signature that is not consistent with a ferrous composition but rather a more typically ferric and "dusty" composition (spectrum 7 in Figure 3). Additionally, we do not observe any spectral indications of ice in this mantle. Spectrally, this is distinct from the dark-toned terrain incised by the PPLs and identifies the light-toned terrain as being geologically distinct from the latter. This result is in line with our previous stratigraphical observations suggesting that the light-toned mantle postdates the dark terrain, and is therefore not the cause of the ice enrichment in this region (Soare et al., 2012a-b).

\section{Interpretation of sediment origin}

The dark-toned terrain exhibits characteristics that are consistent with erosion and aeolian transport of a sedimentary unit, including wind streaks, accumulation of dark sediments (Fig. 5), and one dune field located just north of our study region (Horgan and Bell, 2012). The dark toned terrain also exhibits possible layers in the walls of some scalloped depressions (Fig. 5). If these dark-toned sediments in $U P$ are indeed glass-rich, we hypothesize that they may have originally formed either as impact-associated ejecta or volcaniclastic sediments. In either scenario, the sediments may have been laid down directly due to distal ballistic or atmospheric fallout, or may have been deposited elsewhere and then transported to their current location via other sedimentary processes (fluvial/outflow, aeolian, etc.). However, crater walls in this region do not exhibit the clear layers and flow-related stratigraphic landforms that are observed in Acidalia Planitia and interpreted as evidence for flood/fluvial deposits (Salvatore et al., 2014). Instead, crater walls in our study area exhibit massive morphologies without clear layering. While this may be in part due to modification and obscuration by the pervasive periglacial processes that have operated in our study area, this observation leads us to favour an air fall-deposition model for the sediments in UP. This hypothesis is also more consistent with the very Late Amazonian Epoch age for these 
deposits than flood/fluvial deposition, as this time period post-dates outflow channel activity (Tanaka et al., 2003).

Several authors propose that there should be globally-distributed impact melt-droplets (sub-mm size) on Mars even from relatively small craters (Lorenz 2000; Schultz and Mustard 2004). Given estimates of current cratering-rates, these same authors suggest that ejecta layers on the order of tens of $\mu \mathrm{m}$ to $\mathrm{mm}$ thick could accumulate every $\sim 10^{4}-10^{5}$ years. Derivatively, ejecta layers thick enough to be incised to tens or hundreds of metres of depth by the scalloped depressions would require on the order of $\sim 10^{8}-10^{9}$ years to accumulate, effectively approaching the full Amazonian Epoch time-period. This is inconsistent with the most recent age-estimates of the surface in and around the mid-latitudes of $U P$, all of which point to the terrain having been formed very recently, in the very Late Amazonian Epoch (e.g. Mustard et al., 2001; Head et al., 2003; Milliken et al., 2003; Tanaka et al., 2005; Levy et al., 2009a-c; Madeleine et al., 2009, 2014). Although an impact origin for the dark-toned sediments cannot be ruled out, from a geochronological point of view, other sources may be more plausible.

The glass-rich composition of the sediments is also consistent with tephra, more particularly, ash, produced by explosive volcanism. The low albedo is also consistent with many varieties of iron-bearing glass, and is reminiscent of dark and glass-rich volcanic plains in Iceland (Arnalds, 2001; Horgan and Bell, 2012). Modeling of explosive volcanism on Mars points to three key inferences: 1. massive eruptions have been commonplace through the geological history of the planet; 2. eruptions on Mars probably were much more explosive than on Earth due to lower atmospheric-pressure; and 3. dispersion of silt to sand-sized grains of ash (by air fall) can be widespread, thick and layered (Wilson and Head, 2007; Kerber et al., 2012). In particular, Kerber et al. (2012) demonstrate that the airfall deposition of ash from an explosive event centred at Syrtis Major could reach the mid-latitudes of $U P$ where 
the dark-toned terrain is observed when Mars' obliquity is extreme. Other source regions such as Arabia Terra are possible (Kerber et al., 2012) and further investigation is warranted.

Compared to an impact-melt origin, an explosive volcanic origin for these deposits would imply a relatively short deposition-timescale. Moreover, if a major volcanic-event coincided with (or perhaps motivated) a period of enhanced precipitation in $U P$, then this could produce the near-concurrent deposition of sediments and ice that would be required (discussed below) to form decametre thick and ice-rich sediments observed putatively in our study region.

\section{The origin of excess ice to depth on Earth}

On Earth, alases form and are observed in conjunction with small-sized thermalcontraction polygons and polygon-junction pits only where the permafrost ("ground that has been frozen for at least two years", Harris et al., 1988) is characterised by three conditions. First, the permafrost must be "frost susceptible," that is to say, composed of relatively finegrained sediments with small interstices; this enables and facilitates the migration of liquid water through soil pores via cryosuction to a freezing front where ice lensing or "icesegregation" occurs (Harris et al., 1988; French, 2007; also, Hohmann, 1997). Second, the permafrost must comprise "ground ice" ("frozen water presented as lenses, wedges, sheets, seams or irregular masses") that is "ice-rich", also referred to as "excess ice" (Harris et al., 1988). Third, the "excess ice" must have undergone thermal destabilisation. Typically, this occurs in response to local or regional rises of sub-aerial temperatures (Washburn, 1973; French, 2007). To form an alas, the thermal destabilisation engenders thaw, the volumetric loss of meltwater by evaporation or drainage, and settling (or subsidence) of the previously frozen sediments to a new equilibrium-depth below the original reference/surface datum (Washburn, 1973; Harris et al., 1988; French, 2007). 
The minimum depth of the ice-rich permafrost in which alases form can be approximated by means of a rough calculation, assuming that all of the excess ice to the full depth of the alas has been lost. For example, if an alas is $\sim 80 \mathrm{~m}$ deep and the ice-volume of the permafrost in which it has formed is $50 \%$, then the estimated depth of the ice-rich permafrost prior to its destabilisation would be $\sim 160 \mathrm{~m}$; this represents the initial volumetric state of the ice-rich permafrost prior to being thawed (adapted from French, 2007).

Some of the depressions in our study region show depths approaching one hundred metres (Costard and Kargel, 1995; Morgenstern et al., 2007; Soare et al., 2007; Séjourné et al., 2011). If the Earth "alas" analogue is valid, then this depth could be indicative of excess ice that is at least this deep if not deeper still. Were this so, a key question that remains unanswered is the means by which excess ice that is $100 \mathrm{~m}$ or deeper could have formed here.

\section{Ice-enrichment and the formation of deep "excess ice"}

\subsection{Freeze-thaw cycling, volcanic terrain and excess ice in the Kamchatka Peninsula,}

\section{Russia}

The Kamchatka peninsula in eastern Russia $\left(\sim 56^{\circ} \mathrm{N}\right)$ hosts thirty-six volcanoes that are classified as 'active' (Kamchatka Volcanic Eruption Response Team (KVERT) (http://www.kscnet.ru)). Seven of these volcanoes exhibit elevations in excess of $\sim 3000 \mathrm{~m}$ above sea level. Mean (annual) temperatures are below $0^{\circ} \mathrm{C}$ and permafrost depths reach $\sim 1 \mathrm{~km}$ at some locations (Sone et al., 2006; Abramov et al., 2008). Mean (annual) precipitation of $\sim 1000 \mathrm{~mm}$, punctuated by cold winters and mild summers, engenders abundant freeze-thaw cycling and the formation of a disparate suite of meltwater-associated, periglacial-landforms: small-sized $(\leq \sim 30 \mathrm{~m}$ in diameter) sorted and unsorted polygons (Fig. 6); ice wedges beneath polygon margins and junctures; earth hummocks; solifluction lobes; and needle ice (Sone et al., 2006; Abramov et al., 2008).

Many of these landforms are rooted in the regional (basaltic) volcanic-plateaus and 
plains that have formed as the result of fissure eruptions, the most recent of which occurred in 1975 and 1976 (Abramov et al., 2008). These plateaus and plains are comprised of basaltic lavas, as well as ashes and cinders; these relatively fine-grained volcanoclastic sediments facilitate the formation of excess ice if and when meltwater is available and freeze-thaw cycling takes place. Moreover, the relatively low thermal-conductivity of volcanic sediments permits buried or even near-surface ground ice to persist and survive even when new (and possibly hot) volcanic deposits accumulate at the surface (Sone et al., 2006; Abramov et al., 2008).

Abramov et al. (2008) investigated thirteen borehole sites in this region, the deepest of which is $\sim 25 \mathrm{~m}$; ground ice comprised $\sim 20-80 \%$ of the extracted material by weight. Multiple borehole-samples exhibited discrete near-surface ice wedges embedded epigenetically in the volcanic cinders and scoria produced by the fissure eruptions of 1975 and 1976 (Abramov et al., 2008). Lenses of massive ice (beds or layers essentially of pure ice) were observed deep within the soil column and were overlain by metre and sub-metre horizons of volcanic ash, basalt, sand and/or ice (possibly firnified buried-snow) (Abramov et al., 2008).

The intermittent presence of ice-rich permafrost to depth within the soil column was observed at most of the borehole sites; the importance of this is two-fold. First, it points to multiple episodes of ice enrichment, by means of seasonally or volcanically-induced freezethaw cycling, alternating with multiple episodes of volcanism; second, it highlights the low thermal-conductivity of volcanic material, as the ice-rich structures at depth are preserved beneath metres of volcanically-derived and subsequently-accumulated sediments that may have been hot at the time of deposition.

\subsection{Possible freeze-thaw cycling, volcanic terrain and putative excess ice in Utopia}

\section{Planitia}


Having used the HiRISE, OMEGA, and CRISM data to evaluate the physical and spectral properties of the dark-toned terrain in our study region, we propose that the terrain is comprised of relatively fine-grained sediments; we hypothesise that the terrain could be the indirect depositional product of explosive volcanism. Furthermore, we suggest that the presence of the scalloped depressions, small-sized polygons and polygon junction-pits is a marker of ice-rich terrain, minimally, to decametres of depth. Writ large, our dark-toned terrain formation-hypothesis comprises three key stages (Fig. 7).

\section{Stage 1: Sediment deposition}

Explosive volcanic-events (either singular or episodic and discrete) in Alba Mons, Syrtis Major or Arabia Terra, generate volcanic ash that is deposited by air-fall in our study region. Over time this creates thick (possibly decametres or more) deposits of dark-toned sediments. At high spatial-resolution, the dark-toned terrain exhibits sub-metre boulders and drifts of dark wind-blown sediment (Fig. 3). These drifts rarely coalesce into aeolian bedforms, suggesting (but not necessarily requiring) that the grain size of the sediments generally is smaller than sand (Bagnold, 1941). This is consistent with the grain size of volcanic ash and, as observed in the Kamchatka peninsula, is an ideal sedimentary-medium for the development of ground ice because of its high porosity and "frost susceptibility" (high potential for cryosuction) (French, 2007; also, Hohmann, 1997).

\section{Stage 2: Snow/ice deposition}

Under current boundary-conditions the precipitation and deposition of water ice/frost is seasonal, ephemeral and constrained by latitude; near the northern Martian pole water ice/frost accumulates on the ground during the winter and sublimates in response to rising temperatures in the spring (Appéré et al., 2011). However, numerous researchers suggest that recent higher-obliquities could have engendered north polar ice-cap sublimation and significant global rises of atmospheric water-vapour, temperature and pressure (e.g. Head et 
al., 2003; Forget et al., 2006; Madeleine et al., 2009, 2014). At lower latitudes, this could have been marked by substantial increases in the atmospheric condensation and precipitation of water-ice/snow and its accumulation on the ground, so much so that large-scale ice sheets comprising kilometres of depth would have formed (e.g. Head et al., 2003; Forget et al., 2006; Madeleine et al., 2009, 2014).

Recently, Halevy and Head (2014) have hypothesised that early Mars sustained intermittently-warm (at and above $0^{0} \mathrm{C}$ ) boundary conditions as the result of strong albeit brief episodes of volcanic eruptions and the associated discharge/rise of atmospheric greenhouse-gases. This would have generated transiently-higher atmospheric $\left(\mathrm{H}_{2} \mathrm{O}\right)$ vapourpressures, as surface deposits of ice and snow evaporate or sublimate, as well as enhanced rates of precipitation when the water-vapour condenses (Halevy and Head, 2014). We suggest that a similar procession of events, derived of explosive volcanism, could have generated local melt-tolerant conditions in the late Amazonian Epoch at the mid-latitudes of UP.

\section{Stage 3: Freeze/thaw cycling}

Ground ice, let alone excess ice, begins to form as snow or ice at or near the surface melts, migrates into the underlying fine-grained and frost-susceptible terrain and then freezes in situ. The build-up of excess ice during freezing is driven by the difference in chemical potential between freezing ice and liquid water driving water toward a freezing front(s) (Dash et al., 2006); iterations of this process create epigenetic ice-lenses, wedges, seams or irregular-masses, much as it has in the ice-rich volcanic terrain of the Klyuchevskoy National Park.

We propose that the ice-enrichment of the (decametre-deep) dark-toned terrain at the mid-latitudes of $U P$ occurred episodically and cyclically: discrete layers of fine-grained and volcanically-derived ash accumulated alternately with discrete layers of snow and/or ice. This assumption is consistent with the possible stratification observed in some scalloped 
depressions (Fig. 5). Moreover, and as noted above, the relatively low-thermal conductivity of ash or other volcanic sediments would enable surface, near-surface or buried snow or ice to persist and survive even when new deposits of these sediments accumulate at the surface.

Extended periods of alternating deposition, accumulation and thaw-freeze cycling could produce horizons or layers of ice-rich volcanic terrain metres to possibly hundreds of metres deep, even if the individual and alternating layers of ash and snow or ice are relatively thin. In addition to our proposed analogue site at Kamchatka, this scenario is also akin to the emplacement and formation of (perennial and persistent) niveo-aeolian deposits of sand and snow in the McMurdo Dry Valleys, Antarctica (Cailleux, 1972; Heldmann et al., 2012), and of (annual and ephemeral) deposits of sand or silt and snow layers at Poste-de-la-Baleine, Quebec, Canada (Cailleux, 1972).

Cyclical excursions above and below $0^{0} \mathrm{C}$ do not require aerial and sub-aerial boundary conditions that are radically different from current ones. Even under current conditions on Mars, liquid water is thought to be meta-stable where thin ice is sheltered locally in small depressions and gully alcoves and is illuminated by normal-incidence insolation (Hecht, 2002; also see e.g. Levy et al., 2009c; Schon and Head, 2011, 2012). If the presence of surface and near-surface ground ice is integrated with estimates of Martian degree days (above $0^{0} \mathrm{C}$ and below the boiling point of water), then "favourable" regions where water could currently be stable locally comprise $29 \%$ of the Martian surface (Haberle et al., 2001). Punctuated by the type of volcanic activity discussed by Halevy and Head (2014) or hypothesised by us, these favourable conditions could have been in place throughout the period when the decametres-deep excess-ice formed in $U P$.

\section{Alternate formation hypotheses}

\subsection{Vapour diffusion and condensation}

\subsection{1.: Vapour diffusion and condensation: a model}


Although the possible meta-stability of highly-localised pockets of water on Mars

today is acknowledged by many researchers, very few of them believe that liquid water is/has been stable at the mid-latitudes of $U P$ for a period of time sufficient to form the scalloped depressions by means of melting and evaporation (Mellon and Jakosky, 1993, 1995; Shorghofer and Aharonson, 2005; Hudson et al., 2009; Shorghofer and Forget, 2012). Thus, if the depressions are alases that evolved in an ice-rich medium, possibly excess ice, then the origin of the excess ice could only be explained by means of atmospheric diffusion and adsorption/condensation (e.g. Morgenstern et al., 2007; Lefort et al., 2009).

Multiple models of (global) atmospheric circulation suggest that the sublimation of the perennial polar-caps and the derived (global) abundance of atmospheric water-vapour vary in response to changes of Mars spin axis and eccentricity (e.g. Mellon and Jakosky, 1993, 1995; Head et al., 2003; Madeleine et al., 2009, 2014). For example, higher obliquities could induce increased polar-sublimation and, in so doing, enhance the global abundance of atmospheric water-vapour. This would facilitate the diffusion, saturation, and condensation of water vapour (as ground ice) within the interstices or pore space of near-surface regolith at non-polar latitudes.

Some diffusion and condensation models show that during periods of high obliquity seasonal thermal-oscillations at the mid-latitudes could drive water vapour into the pore space of near-surface regolith, forming ground ice to as much as ten metres of depth (Mellon and Jakosky, 1993, 1995); however, the oscillations would be too weak to fill all of the available pore space and excess ice could not form, even close to the surface (Mellon and Jakosky, 1995).

The inability of the oscillations to form excess ice largely is the result of three variables: (a) the shortness of time and of depth/intensity that characterises thermal oscillation driven by seasonality; (b) to the extent that the upper few metres of regolith 
approach ice saturation more quickly than the metres at a greater depth, this forms a diffusive barrier that chokes the further transport of vapour to depth; and to a lesser degree, (c) the geothermal gradient, whose temperature raises the required density of vapour-saturation beyond that which can be achieved by condensation at $\geq 10 \mathrm{~m}$ (Mellon and Jakosky, 1995). Deeper ground ice, let alone the possibility of excess ice, is explained by ice having been buried antecedent to the most recent changes of orbital parameters or by the upward transport and freezing of vapour derived of a deep ground-water table (Mellon and Jakosky, 1995)

More recently, Fisher and Lacelle (2014, also see Fisher, 2005) have used data and observations associated with the Phoenix Lander site to suggest that the penetration depth of thermal contraction-cracking can facilitate the transport and concentration of water vapour to a few metres of depth, sufficiently so to form excess ice. Excess-ice that possibly comprises decametres of depth, however, is not considered.

\subsubsection{Excess ice formation by vapour diffusion and condensation on Earth}

The McMurdo Dry Valleys of the Antarctic exhibit sub-zero temperatures and hyperaridity similar enough to Mars for this polar region to serve as a possible Mars (climatological) analogue (Marchant et al., 2002; Levy et al., 2009c; Lacelle et al., 2011, 2013; Marinova et al., 2011; 2013). Interestingly, at various locations within the Dry Valleys ice-rich permafrost has been identified but only within a metre or so of the surface (French and Guglielman, 2000; Bockheim and Hall, 2002; Lacelle et al., 2011, 2013; Marinova et al., 2011; 2013). This near-surface ground (sometimes excess) ice is thought to have formed epigenetically, under the temperature regimes and rises associated with inter-glacial/glacial periods, and by means of vapour-diffusion and condensation (Lacelle et al., 2011; also, Marchant et al., 2002; Lacelle et al., 2013; Marinova et al., 2011, 2013).

\subsection{Ice-dust mantle degradation}

Some researchers propose that the spatially-associated suite of PPLs at the mid- 
latitudes of $U P$ comprises the degradational remnants of a light-toned and region-wide icedust mantle (e.g. Tanaka et al., 2005; Morgenstern et al., 2007; Lefort et al., 2009; Levy et al., 2009a-c, 2010; Ulrich et al., 2010). This mantle is thought to have formed by means of atmospheric precipitation during the very late Amazonian Epoch, under the meteorological influence of changes in the spin axis and/or its orbital eccentricity of Mars (Head et al., 2003; Madeleine et al., 2009, 2014).

Our recent work (Soare et al., 2012a), in line with the observations reported above, shows that the PPLS in our study region incise terrain that is dark-toned, not light-toned (Figs. 2-3); we also noted that wherever the dark and light-toned terrains are observed together, the dark-toned terrain either underlies the light-toned terrain or it resides at a lower elevation (Soare et al., 2012a). Consequently, the light-toned terrain post-dates the dark-toned terrain, could not be its geological (degradational) precursor and cannot comprise the periglacial medium out of which the scalloped depressions and the two other PPLs have formed. Thus, although the light-toned mantle may contain ice, long-term periglacial modification processes appear to be concentrated in the underlying and older dark terrain.

\section{Discussion and conclusion}

Agreement is widespread within the community of Mars researchers that the scalloped depressions and the spatially-associated PPLS are indicative of ice-rich terrain that is tens of decametres deep (e.g. Costard and Kargel, 1995; Morgenstern et al., 2007; Soare et al., 2007, 2008; Lefort et al., 2009; Séjourné et al., 2011). On the other hand, except for the work of a few researchers (Morgenstern et al., 2007; Séjourné et al., 2012; Soare et al., 2012), robust discussions of region-wide processes, lithologies, and cryostratigraphies required to induce ice enrichment to decametres of depth is unapparent in the literature.

Previous studies have shown that many regions covered in dark-toned surface sediments elsewhere in the northern plains are consistent with weathered iron-bearing glass 
(Horgan and Bell, 2012). In this study, we have used the OMEGA and CRISM data in mid$U P$ to show that the spectral properties of the dark-toned terrain incised by the scalloped depressions and two other PPLs are spectrally consistent with weathered glass-rich basalt, similar to weathered volcanic tephras on Mauna Kea. We also draw upon the dark-toned and volcanic terrain in Kamchatka as an analogical foundation for three assumptions about the possible formation of ice-rich terrain in our study region.

First, sediments similar in composition and origin to those deposited around the Kamchatkan volcanoes could have been delivered, deposited and accumulated to depth (perhaps episodically) in mid- $U P$, probably by air fall, as the result of explosive volcanism. Intertwined with this air-fall deposition of volcanic material would be the seasonal (under the influence of disparate orbital eccentricities and/or obliquities) or volcanically-induced (by means of enhanced higher temperatures and enhanced water-vapour abundances in the atmosphere) deposition of snow or ice.

Second, on Mars as on Earth the permeability and porosity of volcanically-derived sediments make them an ideal medium for the infiltration and subsequent (epigenetic) freezing of meltwater, but only in as much as appropriate triple-point conditions are in place. Recent work by a number of researchers points to explosive volcanism possibly having generated aerial and sub-aerial boundary conditions in mid-UP during the late Amazonian Epoch that are at least transiently consistent with the freeze-thaw cycling of surface and nearsurface water-ice or snow.

Third, the relatively low thermal-conductivity of volcanic sediments facilitates the preservation or survival of ground ice at depth, even when it undergoes burial by fresh and potentially hot volcanic-sediments that are deposited subsequent to the formation of that ground ice. We suggest that the dark-toned terrain incised by the PPLs and scalloped depressions is ice-rich to depth and that its ice-enrichment is the work of snow/ice surface 
deposits that have undergone freeze-thaw cycling and burial.

We cannot rule out atmospheric diffusion and vapour condensation as the process by which ground ice forms in the near-surface regolith of our study region, but the leading vapour diffusion/condensation models and hypotheses do not account for the formation of excess ice to decametres of depth on Mars. Moreover, in as much as there are no observed field-sites on Earth where decametres-deep excess ice has been formed by vapour diffusion and condensation, the empirical validation of the diffusion and condensation models and hypotheses awaits further work.

\section{Acknowledgments}

We would like to thank an anonymous reviewer for helpful comments, questions, and advice. SJC is funded by a Leverhulme Trust Grant RPG-397 and by a research grant channeled through RJS. M.R.EL-M is funded by the Swiss National Science Foundation (SNF).

\section{References}

Abramov, A., Gruber, S., Gilchinsky, D., 2008. Mountain permafrost on active volcanoes: Field data and statistical mapping; Klyuchevskaya volcano group, Kamchatka, Russia. Permafrost and Periglacial Processes 19: 261-277, doi:10.1002/ppp.622.

Adams, J.B., 1968. Lunar and Martian surfaces: petrologic significance of absorption bands in the near-infrared. Science 159, 3, 1453-1455, doi:10.1126/science.159.3822.1453.

Arnalds, O., Gisladottir, F.O., Sigurjonsson, H., 2001. Sandy deserts of Iceland: an overview. Journal of Arid Environments 47, 3, 359-371, doi:10.1006/jare.2000.0680.

Bagnold, R.A., 1941. The physics of wind-blown sand and desert dunes. Methuen, London $265 \mathrm{p}$.

Bibring, J.P. et al., 2005. Mars surface diversity as revealed by the OMEGA/Mars Express observations. Science 307, 5, 1576-1581, doi:10.1126/science.1108806.

Bockheim, J.G., Hall, K.J., 2002. Permafrost, active-layer dynamics and periglacial 
environments of continental Antarctica. South African Journal of Science 98, 82-90.

Cailleux, A., 1972. Les formes et dépôts nivéo-éoliens actuels en Antarctique et au Nouveau Québec. Cahiers de géographie du Québec 16, 39, 377-409.

Costard, F.M., Kargel, J.S., 1995. Outwash plains and thermokarst on Mars. Icarus 114, 1, 93-112, doi:10.1006/icar.1995.1046.

Dash, J.G., Rempel, A.W., Wettlaufer, J.S., 2006. The physics of pre-melted ice and its geophysical consequences. Reviews of Modern Physics 78, 695-741, doi:10.1103/ RevModPhys.78.695.

Fischer, E.M., Pieters, C.M., 1993. The continuum slope of Mars: bidirectional reflectance investigations and applications to Olympus Mons. Icarus 102, 2, 185-202, doi:10. 1006/icar.1993.1043.

Fisher, D.A., 2005., A process to make massive ice in the martian regolith using long term diffusion and thermal cracking. Icarus 179, 387-397, doi:10.1016/j.icarus.2005.07. 024.

Fisher, D.A., Lacelle, D., 2014. A model for co-isotopic signatures of evolving ground ice in the cold dry environments of Earth and Mars. Icarus 243, 454-470, doi.org/10.1016/j.icarus.2014.08.009.

Forget, F., Haberle, R.M., Montmessin, F, Levrard, B., Head, J.W., 2006. Formation of glaciers on Mars by atmospheric precipitation at high obliquity. Science 311, 368371, doi:10/1126.science.1120335.

French, H.M., 2007. The periglacial environment, $3^{\text {rd }}$ ed., J. Wiley \& Sons, West Sussex, England, $458 \mathrm{p}$.

French, H.M., Gulgielman, M., 2000. Frozen ground phenomena in the vicinity of Terra Nova Bay, Northern Victoria Land, Antarctica: a preliminary report. Geografiska Annaler 82A, 513-526. 
Haberle, R.M., McKay, C.P., Schaeffer, J., Cabrol., N.A., Grin. E.A., Zent, A.P., Quinn, R., 2001. On the possibility of liquid water on present-day Mars. Journal of Geophysical Research 106, E10, 23,317-326.

Halevy, I., Head, J.W., 2014. Episodic warming of early Mars by punctuated volcanism. Nature Geoscience 7, 865-868, doi:10.1038/ngeo2293.

Harris, S.A, French, H.M., Heginbottom, J.A.., Johnston, G.H., Ladanyi, B., Sego, D.C., van Everdingen, R.O., (eds.), 1988. Glossary of permafrost and related ground-ice terms. Technical Memorandum 142, Permafrost Subcommittee, National Research Council of Canada.

Hauber et al., 2011. Periglacial landscapes on Svalbard: Terrestrial analogs for cold-climate landforms on Mars, in Garry. W.B., and Bleacher, J.E., eds., Analogs for planetary exploration: Geological Society of America Special Paper 483, 177-201, doi:10.1130/ 2011.2483(12).

Head, J.W., Mustard, J.F., Kreslavsky, M.A., Milliken, R.E., Marchant, D.R., 2003. Recent ice ages on Mars. Nature 426, 797-802, doi:10.1038/nature02114.

Hecht, M.H., 2002. Metastability of liquid water on Mars. Icarus 156, 373-386, doi:10.1006/ icar.2001.6794.

Heldmann, J.L., Marinova, M., Williams, K.E., Lacelle, D., McKay, C.P., Davila, A., Pollard, W., Andersen, D.T., 2012. Formation and evolution of buried snowpack deposits in Pearse Valley, Antarctica, and implications for Mars. Antarctic Science 24, 3 299316, doi:10.1017/S095410 2011000903.

Hohmann, M., 1997. Soil freezing-the concept of soil water potential. State of the art. Cold regions Science and Technology 25, 101-110.

Horgan, B., Bell, J.F., 2012. Widespread weathered glass on the surface of Mars. Geology 40, 391-394, doi:10.1130/G32755.1. 
Horgan, B., Smith, R., Mann, P., Stromberg, J., 2013. New evidence for a weathering origin for the high-silica component of TES surface type 2 on Mars. $44^{\text {th }}$ Lunar and Planetary Science Conference, 3032.

Horgan, B., Cloutis, E.A., Mann, P., Bell, J.F., 2014. Near-infrared spectra of ferrous mineral mixtures and methods for their identification in planetary surface spectra. Icarus 234 , 132-154, doi:10.1016/j.icarus.2014.02.031.

Hudson , T.L., Aharonson, O., Schorghofer N., 2009. Laboratory experiments and models of diffusive emplacement of ground ice on Mars. Journal of Geophysical Research 114, E01002, doi:10.1029/2008JE003149.

Kerber, L., Head, J.W., Madeleine, J.B., Forget, F., Wilson, L., 2012. The dispersal of pyroclasts from ancient explosive volcanoes on Mars: implications for friable layered deposits. Icarus 219, 358-381, doi:10.1016/j.icarus.2012.03.016.

Kraft, M.D., Sharp, T.G., Michalski, J.R., Rampe, E.B., 2007. Combined thermal and nearinfrared spectra of hydrous silica coatings: implications for surface type 2 mineralogy and recent liquid water on Mars. $38^{\text {th }}$ Lunar and Planetary Science Conference, 2241.

Lacelle, D. et al., 2011. Vapor-diffusion origin (condensation-adsorption) in ice cemented permafrost spanning the last $135,5 \mathrm{Ka}$ years in University Valley, Dry Valleys of Antarctica. $5^{\text {th }}$ Mars Polar Conference, 6083.

Lacelle, D., Fisher, D., Clark, I.D., Berinstain, A., 2008. Distinguishing between vapor- and liquid-formed ground ice in the northern martian regolith and potential for biosignatures preserved in ice bodies. Icarus 197, 458-469, doi:10.1016/j.icarus.2008. 05.017 .

Lefort, A., Russell, P.W., McEwen, A.S., Dundas, C.M., Kirk, R.L., 2009. Observations of periglacial landforms in Utopia Planitia with the High Resolution Imaging Science Experiment (HiRISE). Journal of Geophysical Research 114, E04005, doi:10.1029/ 

2008JE003264.

Levy, J., Head, J.W, Marchant, D.R., 2009a. Thermal contraction crack polygons on Mars: Classification, distribution and climatic implications from HiRISE observations. Journal of Geophysical Research 114, E01007, doi:10.1029/2008JE003273.

Levy, J., Head, J.W, Marchant, D.R., 2009b. Concentric crater fill in Utopia Planitia: History and interaction between glacial "brain terrain" and periglacial mantle processes. Icarus 202, 462-476, doi:10.1016/j.icarus.2009.02.018.

Levy, J.S., Head., J.W., Marchant, D.R., Dickson, J.L., Morgan, G.A., 2009c. Geologically recent gully-polygon relationships on Mars: insights from the Antarctic Dry Valleys on the roles of permafrost, microclimates, and water sources for surface flow. Icarus 201, 113-126, doi:10.1016/j.icarus.2008.12.043.

Levy, J.S., Head, J.W., Marchant, D.R., 2010. Thermal contraction crack polygons on Mars: A synthesis from HiRISE, Phoenix, and terrestrial analog studies. Icarus 206, 229252, doi:10.1016/j.icarus.2009.09.005.

Lorenz, R.D., 2000. Microtektites on Mars: volume and texture of distal impact ejecta deposits. Icarus 144, 2, 353-366, doi:10.1006/icar.1999.1603.

Madeleine, J.B., Forget, F., Head, J.W., Levrard, B., Montmessin, F., Millour, E., 2009. Amazonian northern mid-latitude glaciation on Mars: a proposed climate scenario. Icarus 203, 390-405, doi:10.1016/j.icarus.2009.04.037.

Madeleine, J.B., et al., 2014. Recent Ice Ages on Mars: the role of radiatively active clouds and cloud microphysics. Geophysical Research Letters 41, 1-7; doi:10.1002/2014GL O59861

Malin, M.C., Edgett, K.S., 2001. Mars Global Surveyor Mars Orbiter Camera: interplanetary cruise through primary mission. Journal of Geophysical Research 106, E10, 2342923570, doi:10.1029/2000JE001455. 
Marinova, M.M., et al., 2013. Distribution of depth to ice-cemented soils in the highelevation Quartermain Mountains, McMurdo Dry Valleys, Antarctica. Antarctic Science 25, 4, 575-582, doi:10.1017/S095410201200123X.

Marinova, M.M et al., 2011. The high-elevation Dry Valleys of Antarctica as a Mars Polar Analogue: mapping subsurface ice distribution and modeling its stability. $5^{\text {th }}$ Mars Polar Conference, 6051.

McEwen, A.S., et al., 2007. Mars Reconnaissance Orbiter's High Resolution Imaging Science Experiment (HiRISE). Journal of Geophysical Research 112, E5, doi:10.1029/2005JE 002605.

Mellon, M.T., Jakosky, B.M., 1993. Geographic variations in the thermal and diffusive stability of ground ice on Mars. Journal of Geophysical Research 98, E2, 3345-3364.

Mellon, M.T., Jakosky, B.M., 1995. The distribution and behavior of Martian ground ice during past and present epochs. Journal of Geophysical Research 100, E6, 11,78111,799 .

Mellon, M.T., 1997. Small-scale polygon features on Mars: Seasonal thermal contraction cracks in permafrost. Journal of Geophysical Research 102, E11, 25,617-25,628.

Michalski, J.R., Bleacher, J.E., 2013. Supervolcanoes within an ancient volcanic province in Arabia Terra, Mars. Nature 502, 7, 47-52, doi:10.1038/nature12482.

Milliken, R.E., Mustard, J.F., Goldsby, D.L., 2003. Viscous flow features on the surface of Mars: Observations from high-resolution Mars Orbiter Camera (MOC) images. Journal of Geophysical Research 108, E6, 5057, doi:10.1029/2002JE002005.

Milliken, R. et al., 2008. Opaline silica in young deposits on Mars. Geology 36, 11, 847, doi:10.1130/G24967A.1.

Minitti, M., Weitz, C.M, Lane, M.D., Bishop, J.L, 2007. Morphology, chemistry, and spectral 
properties of Hawaiian rock coatings and implications for Mars. Journal of Geophysical Research 112, E5, doi:10.1029/2006JE002839.

Morgenstern, A., Hauber, E., Reiss, D., van Gasselt, S., Grosse, G., Schirrmeister, L., 2007. Deposition and degradation of a volatile-rich layer in Utopia Planitia, and implications for climate history on Mars. Journal of Geophysical Research 112, E06010, doi:10.1029/2006JE002869.

Murchie, S. et al., 2007. Compact Reconnaissance Imaging Spectrometer for Mars (CRISM) on Mars Reconnaissance Orbiter (MRO). Journal of Geophysical Research 112, E5, doi:10.1029/2006JE002682.

Mustard, J.F., Cooper, C.D., Rifkin, M.R., 2001. Evidence for recent climate change on Mars from the identification of youthful near-surface ground ice. Nature 412, 411-414. doi:10.1038/35086515.

Mustard, J.F., Poulet, F., Gendrin, A., Bibring, J.P., Langevin, Y., Gondet, B., Mangold, N., Bellucci, G., Altieri, F., 2005. Olivine and pyroxene diversity in the crust of Mars. Science 307, 1594, doi:10.1126/science.1109098.

Ody, A., Poulet, F., Langevin, Y., Bibring, J.P., Bellucci, G., Altieri, F., Gondet, B., Vincendon, M., Carter, J., Manaud, N., 2012. Global maps of anhydrous minerals at the surface of Mars from OMEGA/MEx. Journal of Geophysical Research 117, E00J14, doi:10.1029/2012JE004117.

Poulet, F., Langevin, Y., Boubin, G., Jouglet, D., Bibring, J-P., Gondet, B., 2008. Spectral variability of the Martian high latitude surfaces. Geophysical Research Letters. 35, 2, 20201, doi:10.1029/2008GL035450.

Salvatore, M.R., Mustard, J.F., Wyatt, M.B., Murchie, S.L., 2010. Definitive evidence of Hesperian basalt in Acidalia and Chryse Planitiae. Journal of Geophysical Research 115, E7, doi:10.1029/2009JE003519. 
Salvatore, M.R., Mustard, J.F., Head, J.W., Cooper, R.F., Marchant, D.R., Wyatt, M.B., 2013. Development of alteration rinds by oxidative weathering processes in Beacon Valley, Antarctica, and implications for Mars. Geochimica et Cosmochimica Acta. 115, 137-161, doi:10.1016/j.gca.2013.04.002.

Schon, S.C., Head, J.W., 2011. Keys to gully formation processes on Mars: relation to climate cycles and sources of meltwater. Icarus 213, 428-432, doi:10.1016/j.icarus. $\underline{2011.02 .020 .}$

Schon, S.C., Head, J.W., 2012. Gasa impact crater, Mars: very young gullies formed from impact into latitude-dependent mantle and debris-covered glacier deposits. Icarus 218, 459-477, doi:10.1016/j.icarus.2012.01.002.

Schultz, P.H., Mustard, J.F., 2004. Impact melts and glasses on Mars. Journal of Geophysical Research 109, E1, doi:10.1029/2002JE002025.

Seelos, F.P., Murchie, S.L., Humm, D.C., Barnouin, O.S., Morgan, F., Taylor, H.W., Hash, C. and team., 2011. CRISM data processing and analysis products update calibration, correction, and visualization, $42^{\text {nd }}$ Lunar and Planetary Science Conference, 1438.

Seelos, K.D., Arvidson, R.E., Jolliff, B.L., Chemtob, S.M., Morris, R.V., Ming, D.W., Swayze, G.A., 2010. Silica in a Mars analog environment: Ka'u Desert, Kilauea Volcano, Hawaii. Journal of Geophysical Research, 115, E4, doi:10.1029/2009JE00 3347.

Seelos, K.D., Seelos, F.P., Viviano-Beck, C.E., Murchie, S.L., Arvidson, R.E., Ehlmann, B.L., Fraeman, A.A., 2014. Mineralogy of the MSL Curiosity landing site in Gale crater as observed by MRO/CRISM. Geophysical Research Letters 41, 14, 48804887, doi:10.1002/2014GL060310.

Seibert, N.M., Kargel, J.S., 2001. Small-scale Martian polygonal terrain: implications for 
liquid surface water. Geophysical Research Letters 28, 899-902.

Séjourné, A., Costard, F.,Gargani, J., Soare, R.J., Marmo, C., 2010. The polygon junction pits as evidence of a particularly ice-rich area in Utopia Planitia. $40^{\text {th }}$ Lunar and Planetary Science Conference, 2113.

Séjourné, A., Costard, F., Gargani, J., Soare, R.J., Fedorov, A., Marmo, C., 2011. Scalloped depressions and small-sized polygons in western Utopia Planitia: a new formation hypothesis. Planetary and Space Science 59, 412-422, doi:10.1016/j.pss.2011.01.007.

Séjourné, A., Costard, F.N., Gargani, J., Soare, R.J., Marmo, C., 2012. Evidence of an eolian ice-rich and stratified permafrost in Utopia Planitia, Mars. Planetary and Space Science 60, 348-254, doi:10.1016/j.pss.2011.09.004.

Shorghofer, N., Aharonson, O., 2005. Stability and exchange of subsurface ice on Mars. Geophysical Research Letters 110, E05003. doi:10.1029/2004JE002350.

Shorghofer, N., 2007. Dynamics of ice ages on Mars. Nature 449, 192-195,doi:10.1038/ nature06082.

Shorghofer, N., and Forget, F., 2012. History and anatomy of subsurface ice on Mars. Icarus 220, 2, 1112-1120, doi:10.1016/j.icarus.2012.07.003.

Singer, R. B., 1982. Spectral evidence for the mineralogy of high-albedo soils and dust on Mars, International Colloquium on Mars, 87, 10159-10168, doi:10.1029/JB087iB12p 10159.

Soare, R.J., Kargel, J.S., Osinski, G.R., Costard, F., 2007. Thermokarst processes and the origin of crater-wall gullies in Utopia and western Elysium Planitia. Icarus 1, 191, 195-212, doi:10.1016/j.icarus.2007.04.018.

Soare, R.J., Osinski, G.R., and Roehm, C.L., 2008. Thermokarst lakes and ponds on Mars in the very recent (late Amazonian) past. Earth and Planetary Science Letters 272, 12, 382-393, doi:10.1016/j.eps1.2008.05.10. 
Soare, R.J., Osinski, G.R., 2009. Stratigraphical evidence of late Amazonian periglaciation and glaciation in the Astapus Colles region of Mars. Icarus 202 (1) 17-21. doi:10. 1016/j.icarus.2009.02.009.

Soare, R.J., Séjourné, A., Pearce, G., Costard, F., Osinski, G.R., 2011. The Tuktoyaktuk Coastlands of northern Canada: a possible "wet" periglacial analogue of Utopia Planitia, Mars, in Garry. W.B., and Bleacher, J.E., eds., Analogs for planetary exploration: Geological Society of America Special Paper 483, 203-218, doi:10.1130/ 2011.2483(13).

Soare, R.J., Conway, S., Costard, F. Dohm, J.M., Séjourné, A., 2012a. Climate change $\&$ the origin of ice-rich permafrost (segregation ice) in mid Utopia Planitia, Mars. Mars Recent Climate Change Workshop. Moffett Field, California.

Soare, R.J., Costard, F.N., Pearce, G., Séjourné, A., 2012b. A re-interpretation of the recent stratigraphical history of Utopia Planitia: implications for late-Amazonian periglacial terrain and an ice-rich mantle. Planetary and Space Science 60, 131-139, doi:10.1016/j.pss.2011.07.007.

Sone, T., Yamagata, K., Otsuki, Y., Sawada, Y., Vyatkina, M., 2006. Distribution of permafrost on the west slope of Mt. Ichinsky, Kamchatka, Russia. Bulletin of Glaciological Research 23. 69-75.

Souness, C.J., Abramov, A., 2012. The volcanic terrains of Kamchatka, eastern Russia: a glacial and periglacial environment with potential for Mars analog-based research. $43^{\text {rd }}$ Lunar and Planetary Science Conference, 1071.

Tanaka, K.L., Skinner, J.A., Hare, T.M., 2005. Geologic map of the northern plains of Mars, scale 1:15,000,000. U.S. Geological Survey Scientific Investigation, Map 2888.

The Kamchatka Volcanic Eruption Response Team: http://www.kscnet.ru/ivs/kvert/index eng.php. 
Ulrich, M., Morgenstern, A., Günther, F., Reiss, R., Bauch, K.E., Hauber, E., Rössler, S., Schirrmeister, L., 2010. Thermokarst in Siberian ice-rich permafrost: comparison to asymmetric scalloped depressions on Mars. Journal of Geophysical Research 115, E10009, doi:10.1029/2010JE003640.

Ulrich, M., Hauber, E., Herzschuh, U., Härtel, S., Schirrmeister, L., 2011. Polygon pattern geomorphology on Svalbard (Norway) and western Utopia Planitia (Mars) using highresolution stereo remote-sensing data. Geomorphology 134, 3-4, 197-216, doi.org/10. 1016/j.geomorph.2011.07.002.

Wan Bun Tseung, J.M., Soare, R.J., 2006. Thermokarst and related landforms in western Utopia Planitia, Mars. Implications for near-surface excess ice. $37^{\text {th }}$ Lunar \& Planetary Science Conference, 1414,

Wilson, L., Head, J.W., 2007. Explosive volcanic eruptions on Mars: Tephra and accretionary lapilli formation, dispersal and recognition in the geologic record. Journal of Volcanology and Geothermal Research 163, 83-97.

\section{Figures}

Fig. 1: Context maps of our study site. (a) Mars Orbiter Camera, wide angle mosaic of Utopia Planitia (UP), box indicates our region of study shown in (c-d). (b) OMEGA mosaic 0.77-1.30 $\mu \mathrm{m}$ spectral slope map of UP. (c) Mosaic of CTX images showing the area of study, red box indicates location of HiRISE image shown in Figure 2a-c, yellow hourglass footprints show locations of CRISM images shown in Figure 3. (d) CTX map with OMEGA spectral-slope map overlain.

Fig. 2: Putative periglacial-landforms $(P P L s)$ at the mid-latitudes of $U P$ and a thermokarst lake-alas complex on Earth. (a) CTX image overview of the periglacially-modified terrain (we suggest) in $U P$; the image shows the spatial relationship between lighttoned (LT) and dark-toned (DT) terrain and materials. CTX image 
P22_009467_2225_XN_42N273W (credit: NASA/JPL/MSSS). (b) Detail of the PPLs in HiRISE image with central colour-strip, showing the qualitative colour difference between the light-toned and dark-toned terrains. Terraces in the walls of the depressions are also visible (tr), as well as polygon margin and junction-pits $(p)$. HiRISE image ESP_026385_2225; $42.305^{\circ} \mathrm{N}, 86.49^{\circ}$ E (credit: NASA/JPL/UofA). (c) Close-up of a scalloped depression, with polygon-margin pits $(p)$ and terraces $(t r)$. HiRISE image ESP_026385_2225 (credit: NASA/JPL/UofA). (d) Oblique aerialimage of thermokarst lake and marginal small-sized polygons, some of whose troughs are filled with water (Tuktoyaktuk Coastlands, northern Canada). The thermokarst lake in the background is $\sim 100 \mathrm{~m}$ across. Image credit: R.J. Soare.

Fig. 3: CRISM observations in SW Utopia (a-c) CRISM footprints over CTX images showing scalloped depressions in CRISM image FRT0000A116 (credit: JHU/APL) (a), crater wall with exposed subsurface units in FRT00009A8B (b), and the bright toned mantle to the south in FRT000098DF (c). Numbered subpanels show surface texture and albedo in sampling areas for CRISM spectra, at locations indicated in A-C, from HiRISE images PSP_009467_2225 $\left(42.223^{0} \mathrm{~N}, 86.321^{0}\right.$ E), PSP_006606_2240 $\left(43.816^{0} \mathrm{E}, 89.514^{0} \mathrm{E}\right)$, and PSP_006962_2215 $\left(41.322^{0} \mathrm{~N}, 90.095^{0} \mathrm{E}\right.$, respectively (credit: NASA/JPL/UofA). (d-f) CRISM spectra from locations shown in (a-c), respectively, corresponding to the numbered locations.

Fig. 4: Laboratory spectra of Hawaiian basaltic glasses, Mauna Kea. All spectra have been scaled to one at their maximum value and are stacked for clarity. Points indicate spectra, lines are smoothed spectra. All spectra are sourced from the Planetary Data System unless otherwise noted. Data are not available for some spectra beyond 2.1 $\mu \mathrm{m}$. (a) Unaltered ash, showing both the spectrum of the bulk ash and size fractions (HWMK513). (b) Altered ash and glass. Top spectrum shows glass sand altered in the 
laboratory (Horgan et al., 2013); next two spectra are naturally altered glassy cooling rinds (Minitti et al., 2007); bottom three spectra are naturally altered ashes (HWMK024, HWMK001, WP006). (c) Altered ash, showing the bulk spectrum compared to various size fractions (HWMK012). Larger-sized fractions resemble leached glass, consistent with laboratory leached glass sand (Horgan et al., 2013), the smallest size fractions resemble palagonite (Singer, 1982), and intermediate size fractions are consistent with a combination of these two end members.

Fig 5: Examples from HiRISE red-channel images of possible layering in the walls of scalloped depressions, which also show polygonal terrain incised into the upper dark unit and drifts of dark sediments. (a) ESP_019950_2250 $\left(44.719^{0} \mathrm{~N}, 88.500^{\circ} \mathrm{E}\right)$ (b) ESP_025831_2260 $\left(45.831^{0} \mathrm{~N}, 90.503^{0}\right.$ E) (c) ESP_026385_2225 $\left(42.305^{0} \mathrm{~N}\right.$, $86.149^{0}$ E (d) ESP_036499_2240 $\left(43.795^{0} \mathrm{~N}, 83.367^{0}\right.$ E) (credit: NASA/JPL/UofA).

Fig. 6: A photograph taken from the southern slopes of Tolbachik (photo grid ref: $55.792^{0} \mathrm{~N}$, $\left.160.317^{0} \mathrm{E}\right)$ looking SE. In the foreground, below the dotted line, the frame shows dark-toned volcanic sediments resulting from an eruption in 1975-76. Thermalcontraction cracks and the polygonised-terrain comprised of them are visible to the left and centre of the frame (insets a and b). Ice wedges, not directly visible in this frame, feed into melt-related groundwater drainage-channels (i); the latter drain towards the camera and then to the south, into the right of the frame. The volcanic cone in the background (ii) is the volcano 'Udina' (2920m/asl). Posky Tolbachik lies out of the frame to the left. Insets (a) and (b) have been colour-enhanced to bring out the polygonised-terrain. Image credit: Colin Souness.

Fig. 7: Schematic diagramme of possible ice-enrichment and the formation of excess ice in the dark-toned terrain observed by us at the mid-latitudes of UP. (a) Dark-toned, relatively fine-grained and frost-susceptible volcanic sediments are emplaced, 
blanketing the landscape in UP. (b) These sediments are superposed by atmospherically precipitated snow and/or ice, either under enhanced obliquityconditions or under climate-excursions caused by the volcanic perturbations. (c) The surface ice/snow is redistributed to depth by thaw, meltwater percolation, freezing and the formation of ice-rich structures in the sediment column. Stages $(a-c)$ or $(b-c)$ can be repeated as often as climatic/volcanic conditions allow. (d) Once emplaced, the near-surface ice-rich sediments are subjected episodically to thermal-contraction cracking and localised thermal-destabilisation, forming the triumvirate of PPLs discussed earlier. 


\section{Highlights}

Suites of putative periglacial landforms $(P P L s)$ occur in mid Utopia Planitia

On Earth, similar assemblages form in ice-enriched permafrost by freeze-thaw cycling

OMEGA/CRISM data show that the PPLS occur in frost-susceptible volcanic terrain

Similar terrain in Kamchatka frames this data in a 3-stage ice-enrichment hypothesis 
Figure

Click here to download high resolution image
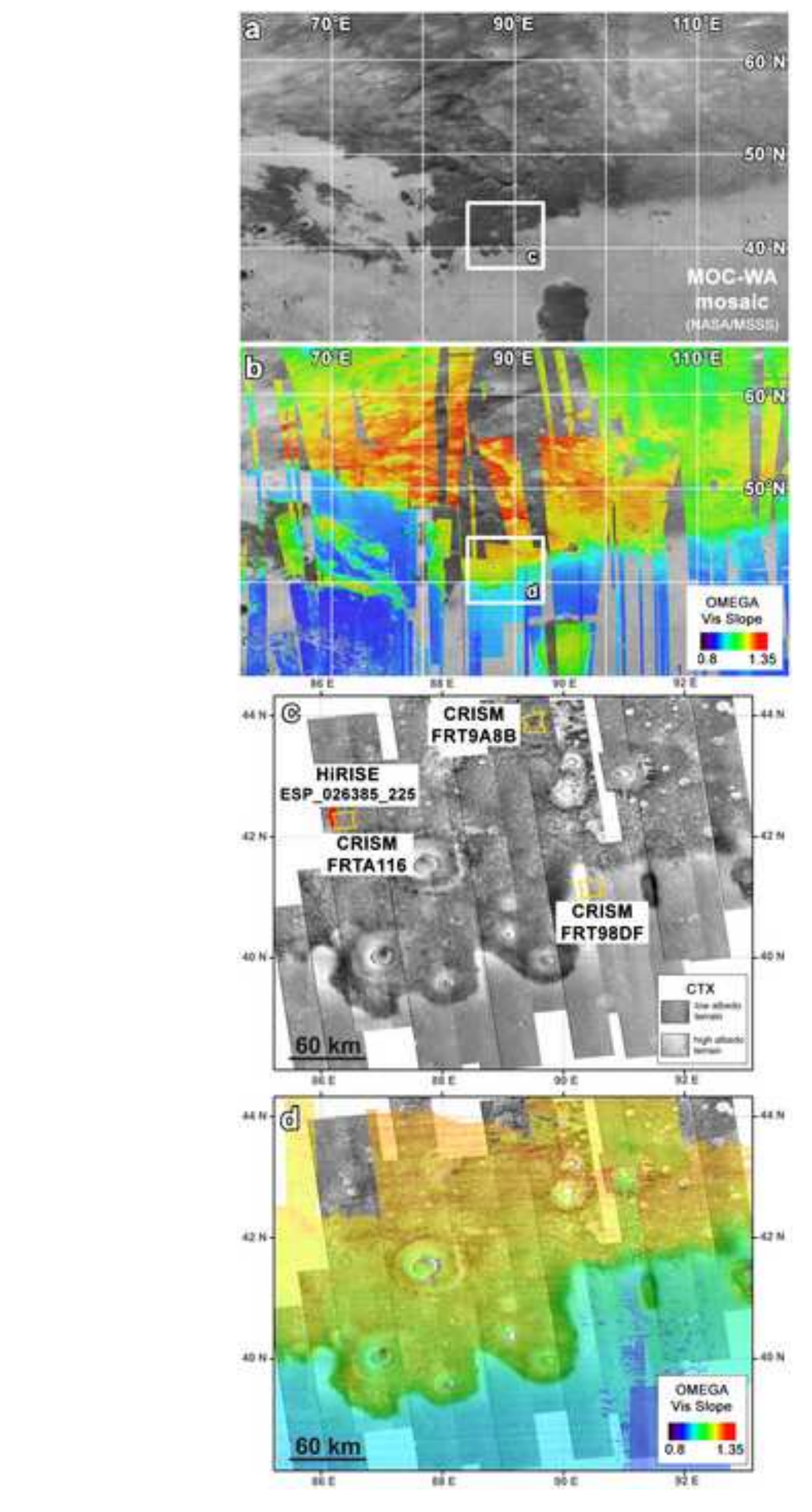
Click here to download high resolution image

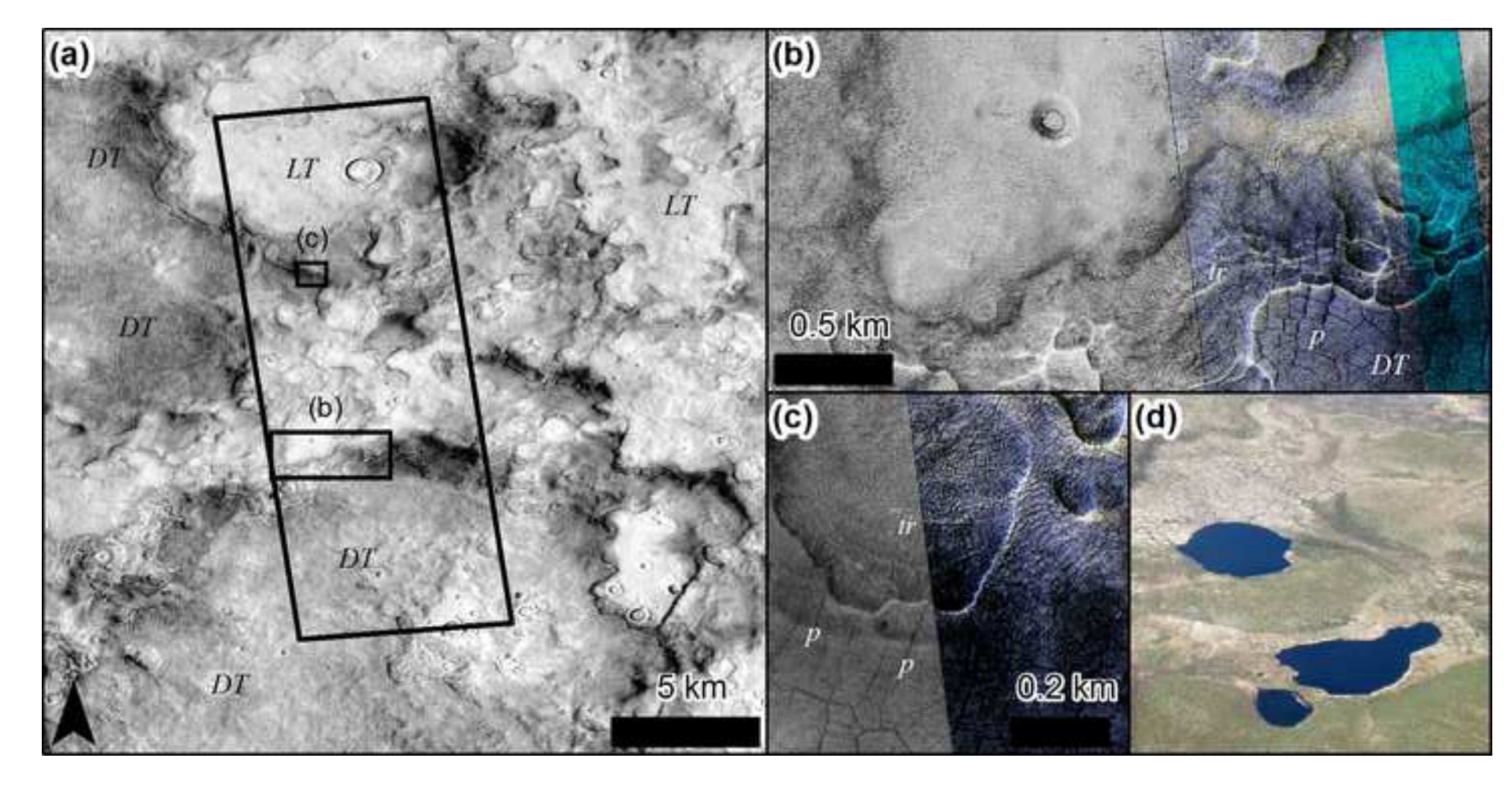



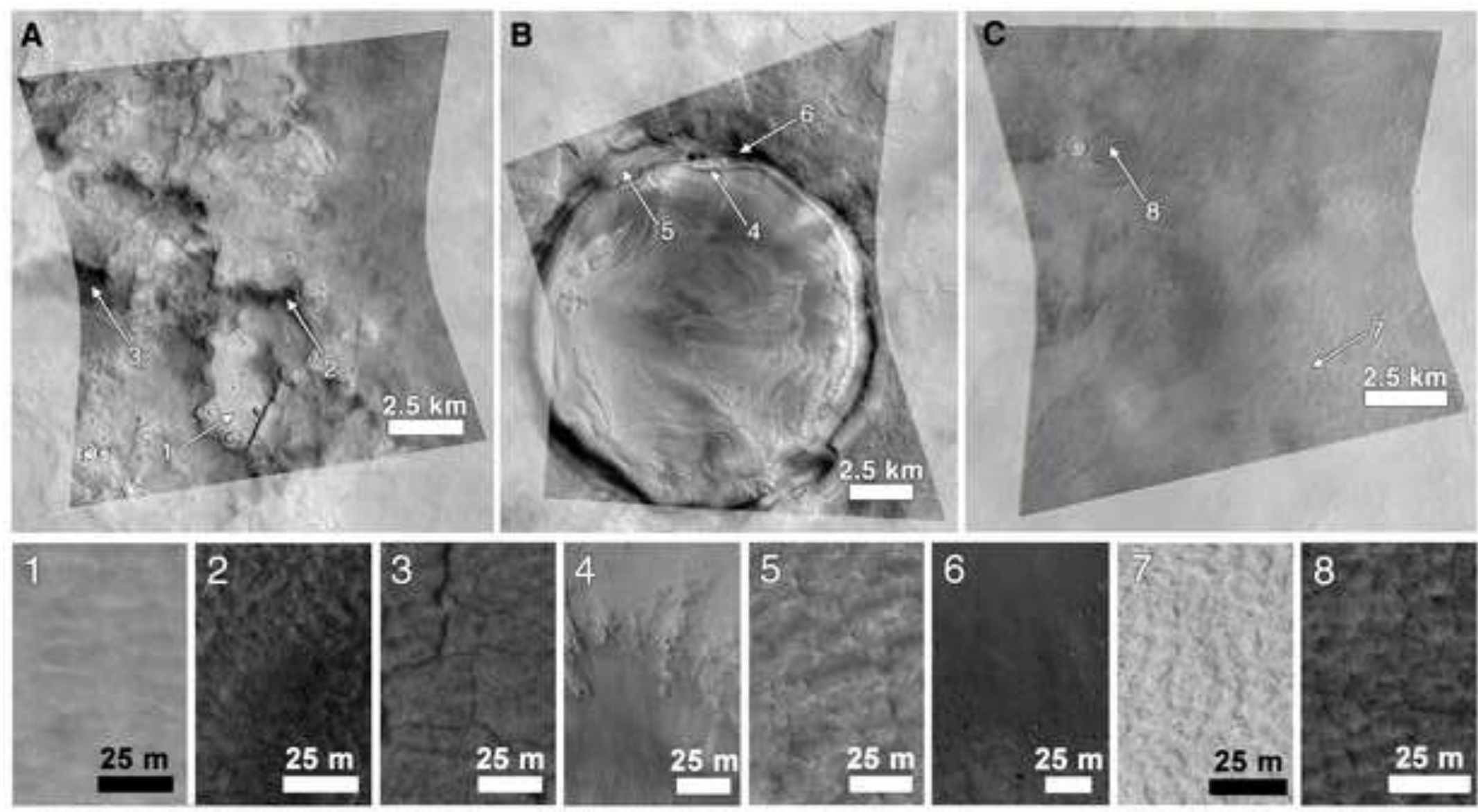

6
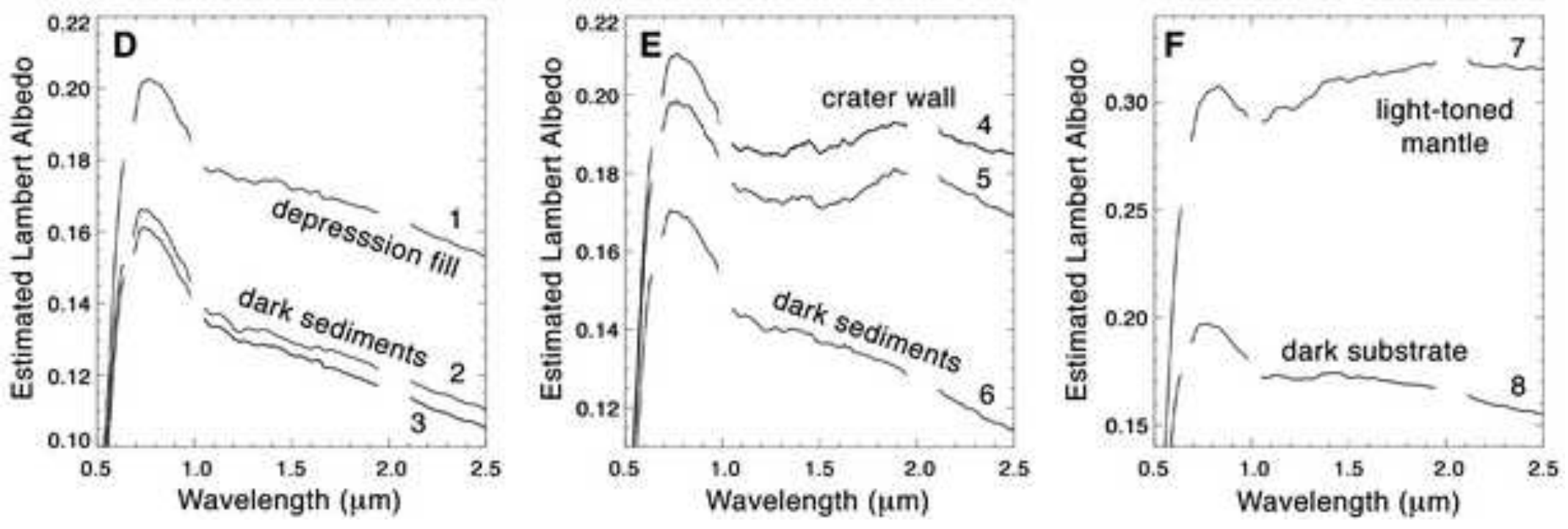

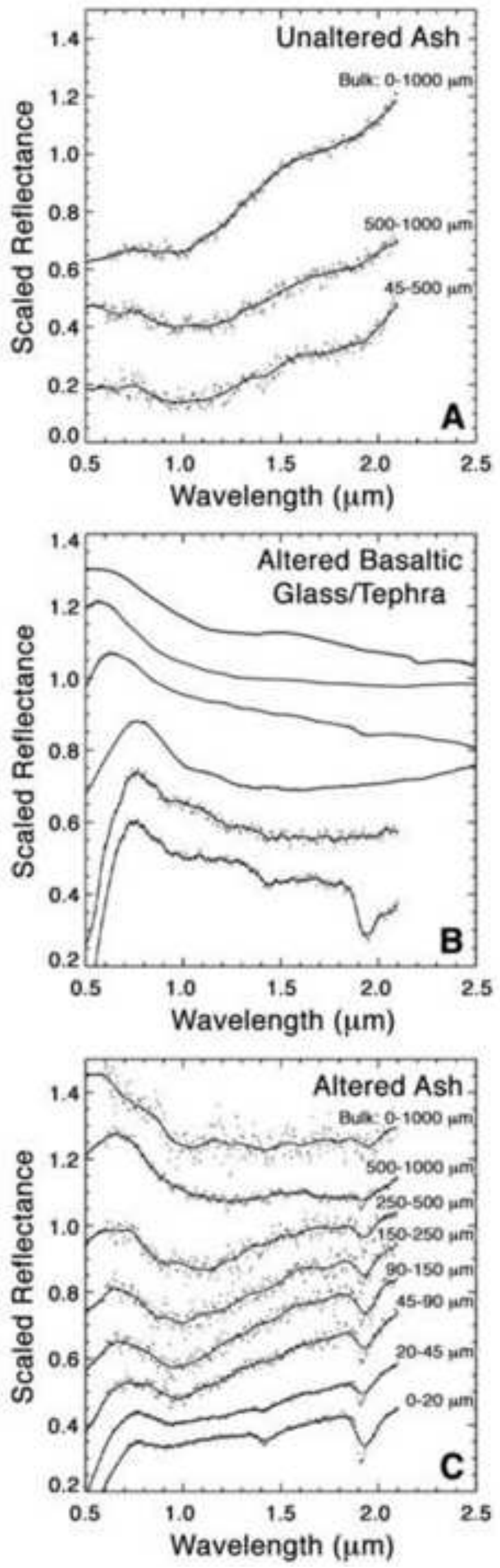

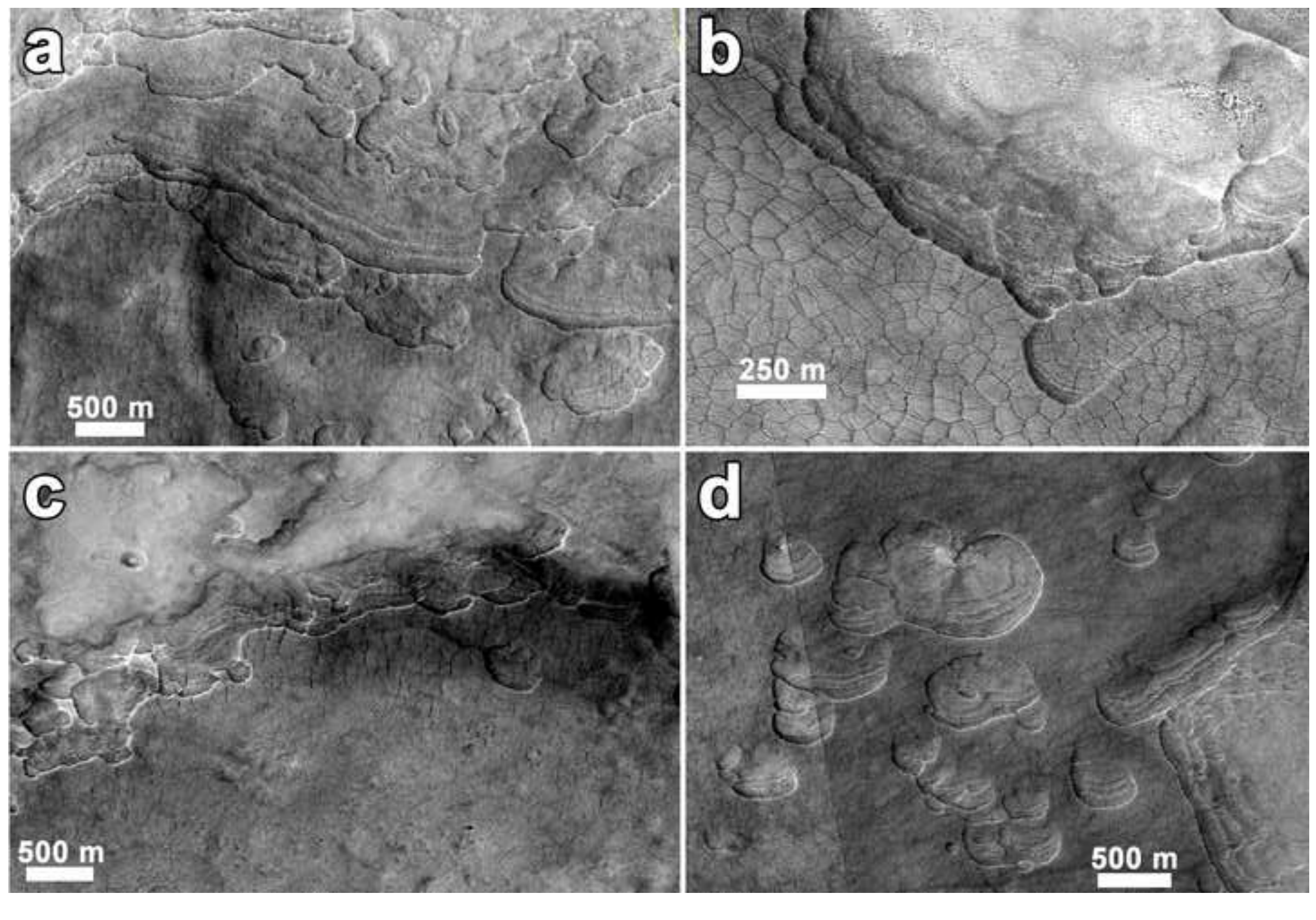$$
\text { re to download high resolution image }
$$

- 
Click here to download high resolution image

(a)

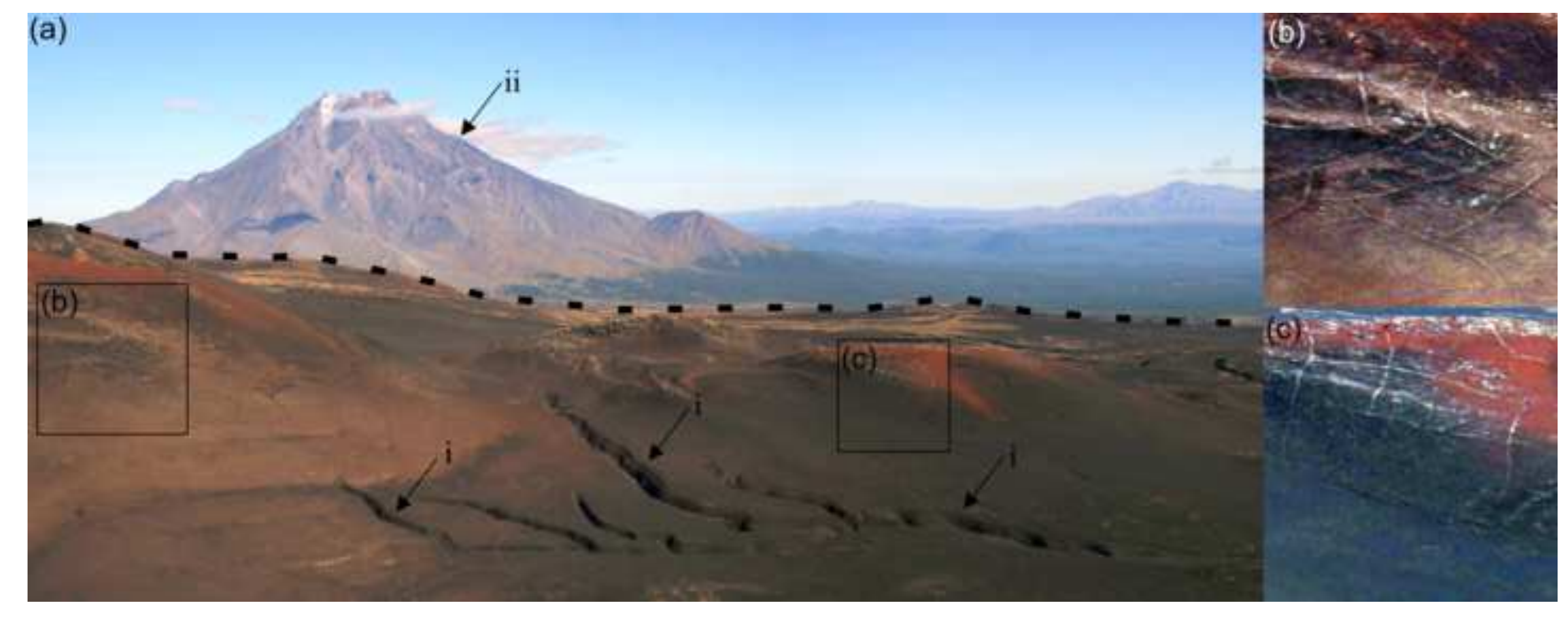

Click here to download high resolution image 
(a)

(b)

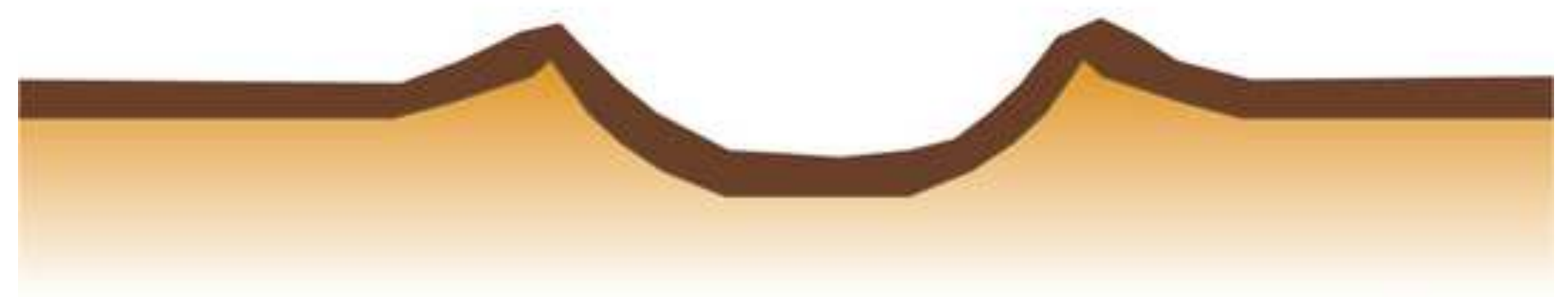

(c)

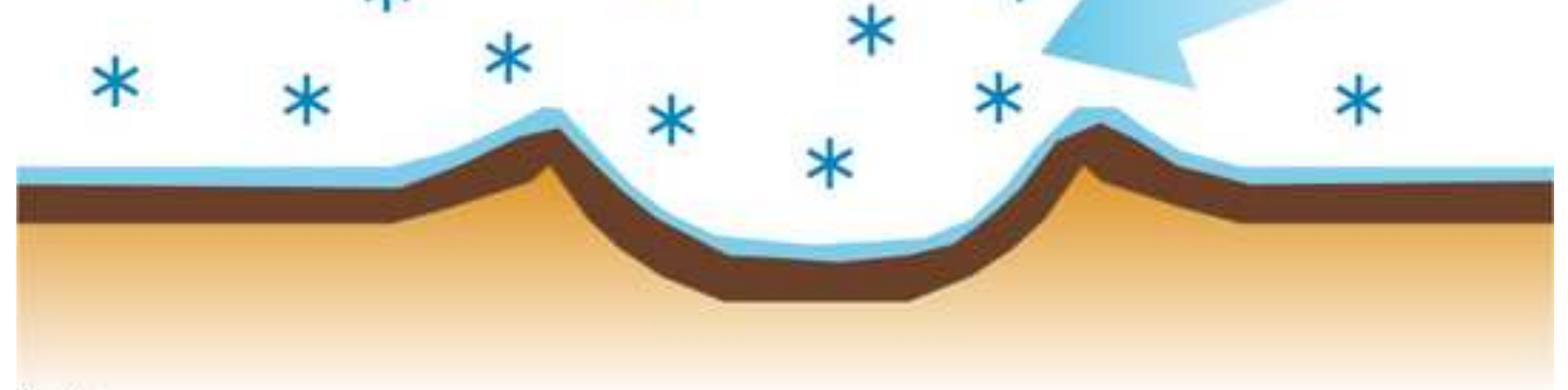

$*$
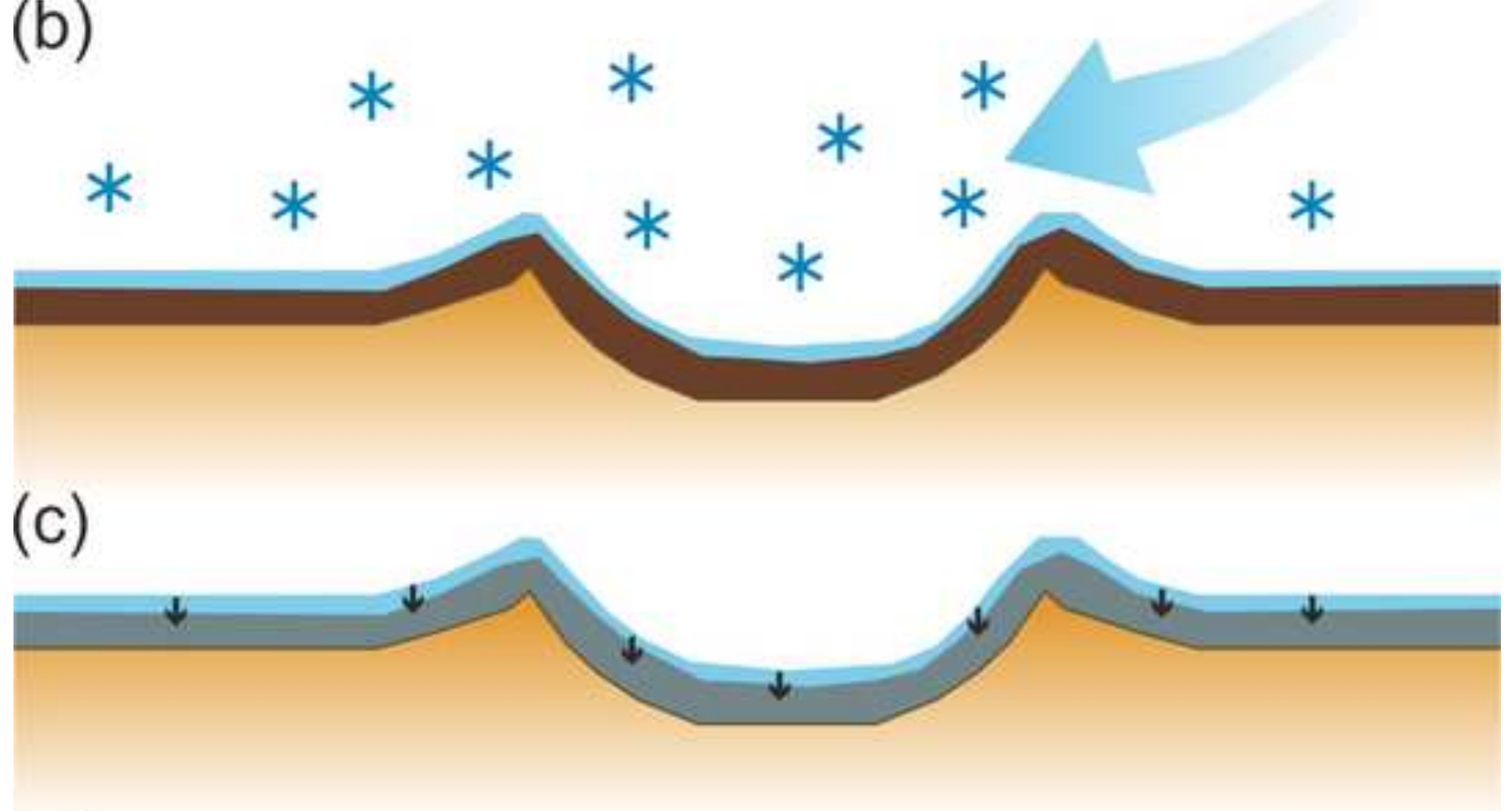

(d)

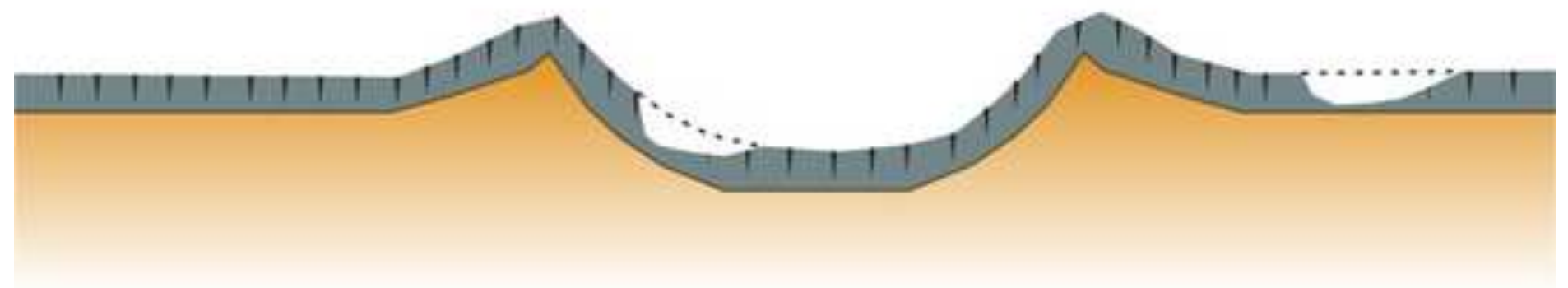

